\title{
Modification of the surface of thermally modified wood with ozone when creating glued structures
}

\author{
Shamil Mukhametzyanov ${ }^{1 * 0000-0002-1371-7583]}$, Ruslan Khasanshin ${ }^{10000-0002-4250-7358]}$, Ruslan \\ Safin ${ }^{10000-0002-0226-4232]}$, Aigul Shaikhutdinova ${ }^{10000-0001-6469-7175]}$, and Albina Safiullina ${ }^{10000-}$ \\ 0002-1728-333X] \\ ${ }^{1}$ Kazan National Research Technological University, 420015, Karl Marks st., Kazan, Russia
}

\begin{abstract}
The greatest interest of researchers is focused on the processes of heat treatment of wood, taking place in an airless environment at temperatures of $180-250{ }^{\circ} \mathrm{C}$, since heat treatment of wood allows increasing its moisture resistance, reduce hygroscopicity, and increase resistance to decay. However, a decrease in the hygroscopicity of wood adversely affects the process of obtaining glued materials due to a decrease in the wettability of thermowood surface and, as a consequence, a decrease in adhesion characteristics. This work is devoted to the study of the effect of ozone on the surface of thermally modified wood to increase the adhesive properties during gluing. It has been determined that the ozonation contributes to an increase in the wettability of the surface layer of thermal wood by more than $15 \%$ due to the reactivity of ozone to oxidize and degrade ligno-containing products of wood. It was revealed that the modification of wood, including preliminary volumetric heat treatment followed by surface treatment with ozone, causes an increase in the strength of the glue line when operated in high humidity conditions. In connection with the results obtained, an improved technology for the production of glued load-bearing structures for wooden housing construction is proposed.
\end{abstract}

Keywords: wood, birch veneer, ozonation, thermal modification, drying, adhesion, adhesive consumption.

\section{Introduction}

The use of wood in construction is due to many factors and has a long history. The foreground is that wood is a durable, lightweight, and environmentally friendly renewable source of raw materials with minimal energy consumption for the manufacture of glued construction materials and products.

However, wood as a structural material, as well as filler in composites has some disadvantages, which include: short service life, relatively low shape stability, significant volumetric moisture deformations, pronounced anisotropy and water absorption.

\footnotetext{
* Corresponding author: joker775.87@mail.ru
} 
At present, chemical methods of biological material processing (acetylation, impregnation, and soaking) are known, where the modification is carried out with various chemical solutions, which are aimed at improving the specific properties of raw materials depending on the required final parameters of the finished product. However, in most cases chemical methods for processing wood filler involve complex technological processes that require multi-stage processing of the material, high capital and operating costs.

In this regard, there is a growing interest in improving the quality of sawn timber using heat treatment.

Thermal modification of wood is carried out at temperatures from $160{ }^{\circ} \mathrm{C}$ to $260{ }^{\circ} \mathrm{C}$ in an oxygen-free environment in special chambers [1]. The main differences between technologies are the environment in which the heat treatment process is carried out: water vapor, oil, inert environment, and vacuum.

Research in the field of technologies and equipment for thermal modification of wood, which allows significantly improving the quality characteristics of the material without the use of chemicals, has been carried out for the last 20 years in many countries leading in woodworking, including Russia, Finland, France, Canada, and Germany.

The performance characteristics of polymer board, obtained on the basis of a wood filler from hard wood pre-modified in a hot liquid were compared with composites based on raw materials [2]. Polypropylene was used as a binder polymer. Based on the studies, an increase in the strength characteristics of polymer composites made of processed filler was found: the strength in static bending increased by $13 \%$, and in tension - by $19 \%$.

An important aspect of the use of pre-heat treatment of wood filler in the production of composite materials is a decrease in the swelling pressure with an increase in the processing temperature, as well as a decrease in the shrinkage and swelling coefficients in proportion to an increase in the temperature of thermal modification [2].

The authors Paul W., Ohlmeyer $M$ et al. [3] noted that with an increase in the processing temperature of wood filler, a decrease in the electromagnetic compatibility of oriented strand board (OSB) was observed. At the same time, as a result of the use of treated wood for the manufacture of boards, the thickness of their swelling significantly decreased without reference to the amount of resin used.

The results of research of thermal characteristics of thermowood are presented in works [4]. It is found that with an increase in the processing temperature, the values of the thermal conductivity and thermal diffusivity of the material significantly decrease, which is explained by the authors by a decrease in the density of wood, as well as a change in its chemical composition.

In the work [5], the possibility of improving the water-repellent properties of plywood materials by means of their thermal oil treatment was studied. As a result, an experimental confirmation of the increase in the water resistance of the finished product when using this method in the manufacture of composites was obtained [6].

The influence of preliminary heat treatment of wood raw materials on the properties of oriented strand board was studied by Paredes J. [7]. The author found that pre-processing, as in the case of chipboard, improved the dimensional stability of OSB. However, if the mechanical properties of OSB made from softwood increased, then when using hardwood, they decrease.

The study of the effect of wood filler thermal modification in the production of woodpolymer composite (WPC) based on low-pressure polyethylene was carried out in the work of Salimgaraeva R.V. [8]. The author revealed a decrease in the mechanical characteristics of the composite with an increase in the processing temperature. The most significant was the decrease in the tensile strength of the material, which reached $20 \%$ for a processing temperature of $240^{\circ} \mathrm{C}$ compared to WPC with untreated filler. The decrease in the compressive strength and static bending strength was significantly less. In addition, the 
author found a decrease in WPC swelling during exposure to water in proportion to an increase in the processing temperature of the wood filler. Microstructural analysis of composites showed a significant decrease in the number and size of micropores with an increase in processing temperature, which is explained by a decrease in gas release from wood when mixing wood filler with a hot polymer. Thus, the author makes the assumption that a decrease in the porosity of the composite causes an increase in such performance indicators as preservation of its appearance and an increase in frost resistance.

A technology for creating cement wood with increased frost resistance, in which the wood filler undergoes preliminary thermal modification, is presented in the work of Aminov L. I. [9]. As a result of the study it was found that the thermal effect on the filler reduced the water-cement ratio, which can be explained by a significant decrease in water absorption by thermally modified wood particles in comparison with untreated ones. The results of studies to determine the adhesion strength of mineral binders to the surfaces of wood of various species before and after heat treatment indicate that heat treatment does not affect adhesion, but often reduces it, which can be explained by deterioration in the wettability of thermowood.

The results of the presented studies indicate an increased interest in the issues of heat treatment of crushed wood in relation to the processes of production of wood-filled composites due to the possibility of increasing the performance characteristics of these materials and, as a consequence, expanding the areas of their possible application.

Thus, the technology of heat treatment of wood provides a material with predictable consumer properties, the most important of which are prolongation of service life, stability of geometric dimensions, rich color range, and high biostability. However, researchers point to a significant decrease in the adhesion of glued compositions to thermowood, which complicates the creation of high-strength glued structures.

At the same time, the technology of ozone treatment of cellulose-containing materials is well known [10]. Ozonation accelerates the surface oxidation process, which leads to the appending a functional (carboxyl) group, contributes to an increase in the wettability and an increase in the free surface energy of wood.

In addition, ozone is used as an oxidizing agent due to the fact that its reactivity allows interacting effectively with organic substances, especially unsaturated aromatic compounds. It should be noted that ozone reactions take place at room temperature and atmospheric pressure [11].

On the example of a number of lignocellulosic materials of paper production it is shown that ozonation leads to an increase in the specific surface area and pore volume of the samples [12]. This type of processing is an effective way of delignification of plant lignocellulosic materials [12].

It is found in the work [13] that lignin is easily oxidized by ozone to low molecular weight products, while hemicellulose and cellulose are relatively resistant to its effects. The use of ozonation as a method of processing biomass to increase its reactivity in the processes of enzymatic hydrolysis into sugars and the production of ethanol is based on this principle [14].

In the study below, we evaluate the possibility of ozone exposure to activate thermally modified wood to increase surface roughness, enhance thermowood wettability and adhesive strength in the manufacture of timber load-bearing glued structures.

\section{Methods and materials}

The study of the effect of ozone treatment on thermally modified wood was carried out on samples of birch, common in the European part of Russia. The choice of birch is due to the fact that it is one of the most widely used hardwoods in Russia. 
By its structure, wood is characterized by significant unevenness of density, porosity and a number of other biological factors affecting the process under study, therefore, careful selection of blanks is required.

Wood blocks with dimensions of $20 \times 100 \times 7 \mathrm{~mm}$ and initial humidity $6 \pm 2 \%$ were prepared as samples for experimental studies of the processes of thermal modification and ozone treatment.

Depending on the plan of the experiment, ozone treatment was carried out for room-dry wood materials, as well as for thermally-modifiedsamples. Thermal modification of the samples was carried out in the temperature range $180-240^{\circ} \mathrm{C}$ by the contact method on an experimental setup [15].

The samples were subjected to two-sided chipping to a thickness of $5 \mathrm{~mm}$ after thermal modification. Chipping is necessary to remove the decomposition products of resinous substances melted onto the surface during heat treatment. [16, 17]

Experiments on ozonation of wood samples in the form of bars were carried out inOZ0500AC ozone chamber of GOTECH Testing Machines Inc. and UGNLab Co., Ltd. Testing Equipment, designed to evaluate the ozone resistance of materials. The plant is equipped with an analyzer based on UV absorption, which provides accurate measurement of the ozone concentration. The ozone chamber allows evaluating the ozone aging of polymeric materials under static and dynamic conditions in the presence of a given ozone concentration. It is able to regulate ozone concentration, air flow rate, and temperature in accordance with international standards.

Experimental studies were carried out as follows: samples of natural and thermally modified birch with a moisture content of $7 \%$ were fixed into the ozonization chamber on a rotating platform. Ozonation was carried out at an ozone concentration of $1000 \mathrm{pphm}$ and an ambient temperature of $50{ }^{\circ} \mathrm{C}$. The duration of the experiment on ozonation of the surface layer of wood samples was 180 minutes.

To analyze the effect of wood samples ozone treatment, control samples were held in a laboratory drying oven LF-25/350-VS1 at a temperature of $50^{\circ} \mathrm{C}$ for a similar duration [18-20]. Then the test samples were removed from the ozonation chamber, and the control samples from the drying chamber.

The prepared samples were divided into two groups: the first group of samples was tested for wettability, and the second was used to create glued beams for subsequent study of the glued structures strength.

The modified wood was examined for wettability. For this, the contact angle was measured using a microscope equipped with an optical protractor. In this work, for the experimental determination of the contact angles of wetting of modified wood, the method of a lying drop was chosen.

Experiments were carried out for samples subjected to thermal modification at different processing temperatures and subsequent modification with ozone. The sample under study was installed on a table, which was in a strictly horizontal position inside the cap. In the course of the study, a drop of $10 \%$ aqueous solution of polyvinyl acetate (PVA) was applied to the surface of the wood by squeezing out from the syringe using a micrometer screw fixed rigidly to the tripod. Moving the syringe stem with a micrometer screw for exactly the same number of divisions allows getting portions of the PVA solution on the surface of the wood of the same size in all experiments. The location of the wood sample was made in such a way that its investigated surface was in line with the optical axis of a horizontal microscope equipped with an optical goniometer and an illuminator. The values of the contact angles were measured with an accuracy of $\pm 0.5^{\circ}$ every 30 seconds of exposure at a constant temperature.

The ultimate bending strength of the glued beam was determined on a universal testing machine according to the standard three-point bending method by plastic deformation of a 
rectangular sample without changing the direction of the force action until complete destruction.

The samples were prepared as follows: wood bars without defects with a cross section of $20 \times 100 \times 7 \mathrm{~mm}$, glued in 3 layers and subjected to preliminary two-stage processing (thermal modification + ozone treatment), were glued over a wide area with glue consumption at the rate of $130 \mathrm{~g} / \mathrm{m}^{2}$. The scheme of bonding and testing of samples is shown in Fig. 1. The glued samples were stored at a temperature of $18-22{ }^{\circ} \mathrm{C}$ for 10 days until the glue was completely cured.

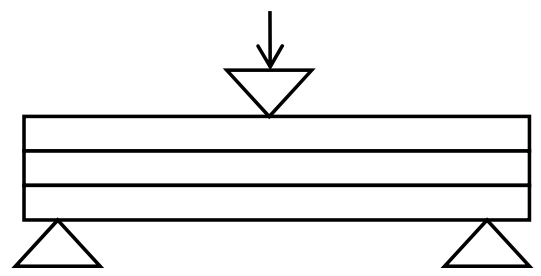

Fig. 1.Scheme of testing samples for the strength of the adhesive seam.

\section{Results and discussion}

The treated wood was examined for wettability. For this, the contact angle was measured using a microscope equipped with an optical goniometer. Surface wetting characterizes a number of technological properties of heterogeneous systems: in casting systems, wetting determines their most important technological property - viscosity, and in composite compositions such as wood - binder, it largely determines the adhesive interaction between wood and binder.

Table 1 graphically shows the changes in the size and shape of the droplet on the control, ozone-treated, and thermally modified samples.

Table 1. Contact angle depending on the type of processing.

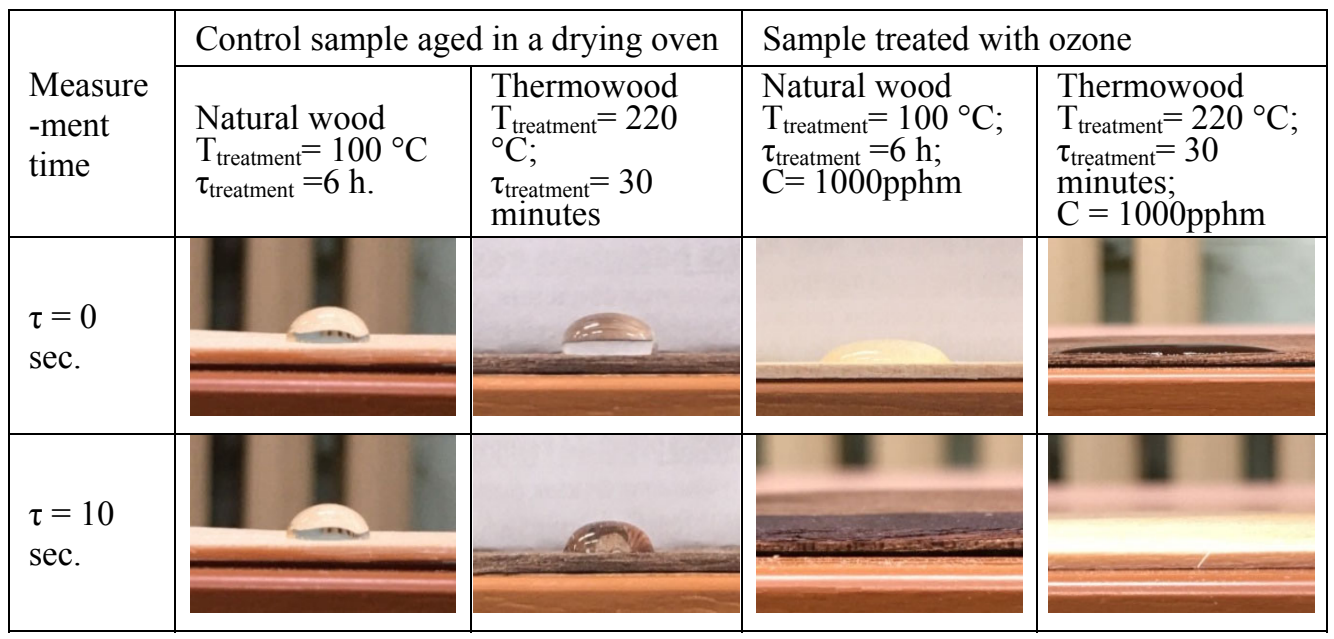

The photographs show that the change in the shape and size of the drop in the first 10 seconds of experiments on control samples are practically not observed. While on samples of natural wood treated with ozone [17], there is a rapid spreading of a drop over the surface of the material. Moreover, the effect of ozonation on the drop spreading is significant both for natural wood and heat treated wood. 
Figure 2 presents the graphical dependences of the effect of ozonation on the contact angle of thermowood (TM) and natural wood, which show a significant increase in the wettability of wood with ozone modification.

The contact angle for wood samples at the initial stage is: for the control sample of TM wood $65^{\circ}$, for the control sample of natural wood $57^{\circ}$, for $\mathrm{TM}$ wood treated with ozone $55^{\circ}$, and for natural wood treated with ozone $53^{\circ}$. It is observed that the contact angle of droplet on the control sample of thermally modified wood [18] practically does not change for 10 seconds, while the contact angle of the thermally modified veneer treated with ozone rapidly decreases and reaches zero. Similar results are observed with natural wood samples. However, it can be noted that the values of the contact angle for the samples of thermally modified wood are higher than the values for the samples of natural wood. This is due to the fact that there is a removal of extractives and a decrease in the amount of hemicelluloses in the structure of wood in the process of high-temperature processing [19], thereby increasing the moisture resistance of the sample.

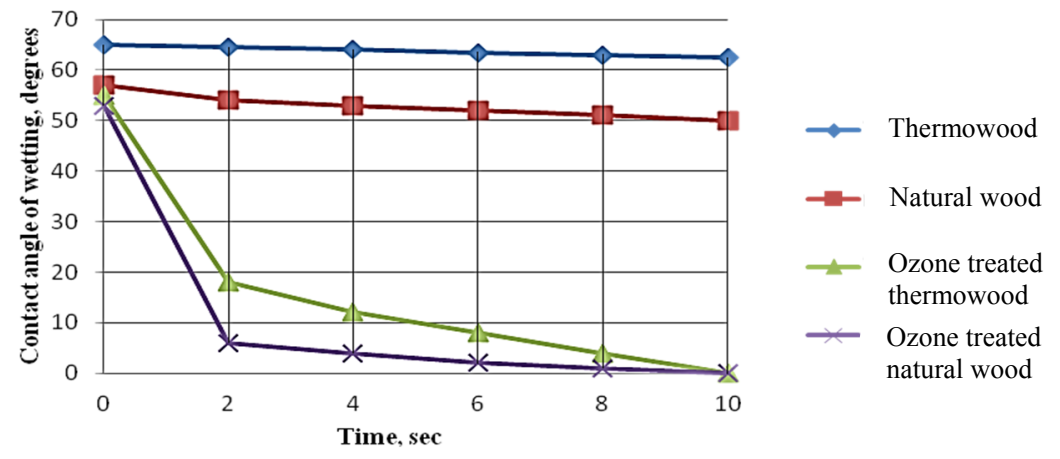

Fig. 2. Influence of ozone and temperature treatment on the contact angle of wood.

The static bending strength tests of glued specimens are presented (Fig. 3). The technique allows us to assess the influence of the modification process on the strength indicators and to predict the physical and mechanical properties of the glued material (Fig. 3a).

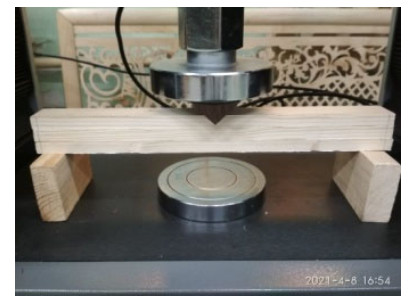

a)

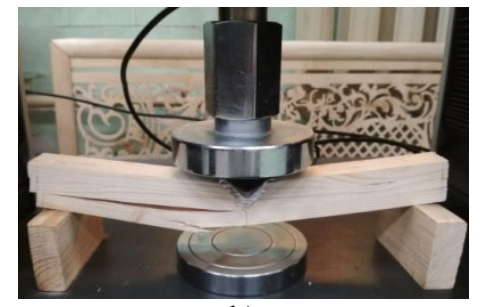

b)

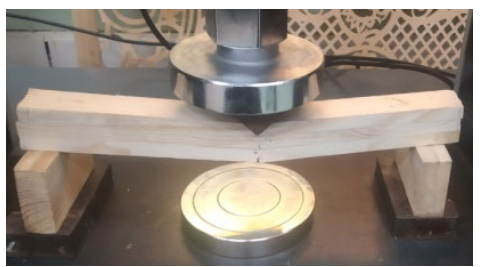

c)

Fig. 3. Flexural strength tests: $a$ - start of tests; $b$ - destruction of the adhesive composition obtained from untreated wood; $\mathrm{c}$ - destruction of a sample from modified wood. 
As can be seen from the photographs (Fig. 3b), a mixed type of failure is observed for glued material from unmodified wood. There is a complex failure of samples from normal stresses and interlaminar shear caused by stresses. In this case, delamination of the glue line is observed. This indicates poor adhesion between the binder and the wood during the bonding process.

In the case of a glued material made of modified (ozone-treated) wood (Fig. 3c), material destruction is observed only from shear stresses. There is no delamination process along the glue line, the structure of the material remains intact, the sample collapsed from the action of the shear stresses of the testing machine, which exceeded the permissible values.

The results of studying the ultimate bending strength of the samples are shown (Fig. 4). It can be seen from the above data that thermal modification reduces the adhesion of the binder to the wood surface, which is explained by the deterioration in the wettability of thermowood. At the same time, ozonation contributes to an increase in the adhesive interaction of the binder with the surface: the combined action of two-stage wood processing, including preliminary thermal modification followed by surface ozone treatment, causes stable adhesion of the binder to wood in comparison with the use of natural wood. It can be used to improve technologies for the production of bearing glued structures from wood, characterized by increased moisture and water resistance.

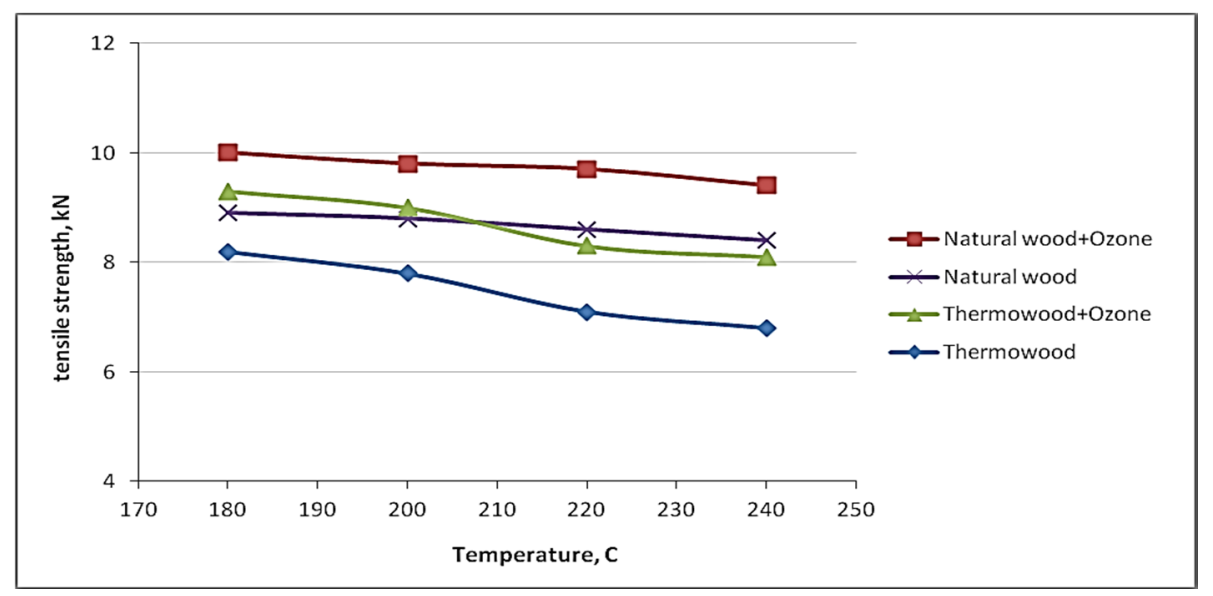

Fig. 4. Studies of the ultimate bending strength of wood samples in the form of glued beams.

\section{Conclusions}

Based on the results of studying the effect of ozone treatment on wood, the possibility of using this type of modification for a comprehensive improvement of the technological characteristics of wood raw materials in the production of glued materials by modifying the micro- and nanostructure of the body is shown.

It is found that thermal modification of wood affects the decrease in adhesion, which can be explained by deterioration in the wettability of the material, while ozonation of thermally modified wood increases the adhesion strength of the binder to the surface of the material.

Based on the studies and the analysis of visual measurements of the contact angle of the studied wood samples, it can be concluded that the ozonation process contributes to an increase in the adhesion properties of the surface layer of the wood material due to the reactivity of oxidizing and degrading ligno-containing wood products. This allows further reduction of the consumption of glue when gluing samples, thereby reducing the emission 
of harmful volatile substances, but also increasing the bearing capacity of the glued wooden building structure.

Thus, in connection with the results obtained, an improved technology for the production of glued bearing wood structures is proposed, in which the ozone treatment of the lamellas is carried out on both sides along the glued layers, providing high adhesion strength.

\section{Acknowledgement}

This work was supported by a grant from the President of the Russian Federation to support at the national level young Russian scientists who have a Ph.D. degree (MK-2246.2020.8)

\section{References}

1. C. Chirat, D. Lachenal, S. Mishra, R. Passas, F. Ludovina, B. Khelifi, Association Technique de L'Industrie Papetiere. ATIP, 61, 43-49 (2007)

2. N.A. Mamleeva, S.A. Autlov, N.G. Bazarnova, V.V. Lunin, International Journal of Current Research, 8 (11), 41714-41721 (2016)

3. W. Paul, M. Ohlmeyer, H. Leithoff, Holz Roh Werkst, 65, 57-63 (2007)

4. O. Hosseinaei, S. Wang, A.A. Enayati, T.G. Rials, Compos Part A Appl S, 43, 686-694 (2012) DOI: 10.1016/j.compositesa.2012.01.007

5. N. Ayrilmis, S. Jarusombuti, V. Fueangvivat, P. Bauchongkol, Polym Degrad Stabil 96, 818-822 (2011) DOI: 10.1016/j.polymdegradstab.2011.02.005.

6. K.J. Kim, T.J. Eom, Journal of Korea TAPPI, 43 (1), 23-28 (2011)

7. J.J. Paredes, The influence of hot water extraction on physical and mechanical properties of $O S B, \mathrm{PhD}$ Dissertation, The University of Maine (2009)

8. R.R. Safin, R.V. Salimgaraeva, E.A. Beliakova, Int. Conf. on Ind. Eng., App. and Man., ICIEAM 2017, 8076473 (2017) DOI: 10.1109/ICIEAM.2017.8076473

9. L.I. Aminov, Improvement of the technology for the production of composite materials based on wood fillers and mineral binders, PhD Dissertation, Kazan, 169 (2011)

10. E.M. Ben'ko, O.R. Manisova, G.P. Murav'eva, V. V. Lunin, Rus. Journ. of Phy. Chem. 87, 1097-1101 (2013) DOI: 10.1134/S0036024413060046

11. A.Kh. Safiullina, Sh.R. Mukhametzyanov, A.R. Shaikhutdinova, M.A. Zhmaylo, The effect of ozonation on the wettability of wood, Conf. Ser.: Mater. Sci. Eng. 986, 27-29 August 2020, 012028 (2020) DOI: 10.1088/1757-899X/986/1/012028

12. G. Ventorim, J.L. Colodette, A. de F. Gomes, L.H.M. da Silva, Wood and Fiber Science, 40 (2), 190-201 (2008)

13. M. Kobayashi, T. Asano, M. Kajiyama, B. Tomita, Journ. of Wood Sci. 51 (4), 348-356 (2005) DOI: 10.1007/s10086-004-0664-9.

14. N.R. Galyavetdinov, R.R. Khasanshin, R.R. Safin, R.G. Safin, E.Y. Razumov, Int.lMultidiscip. Sci. GeoConf. Surv. Geol. and Min. Ecol. Manag. SGEM. 1 (4), 77978 (2015)

15. R.R. Safin, R.R. Khasanshin, I.F. Khakimzyanov, S.R. Mukhametzyanov, P.A. Kainov, Journ. of Eng. Phys. and Thermophys. 90 (2), 310-317 (2017) DOI: 10.1007/s10891017-1569-y

16. K. Guojun, Z. Yijing, N. Yonghao, R.P.A. Heiningen, Journ.of Wood Chem. and Tech. 15 (4), 413-430 (2006) DOI: 10.1080/02773819508009518

17. R.R. Safin, I.F. Khakimzyanov, Sh.R. Mukhametzyanov, Proc. Eng., 206, 1063-1068 (2017) DOI: 10.1016/j.proeng.2017.10.595 
18. F. Pouyet, C. Chirat, D. Lachenal, BioRes. 8 (4), 5289-5298 (2013) DOI: 10.15376/biores.8.4.5289-5298

19. S.R. Mukhametzyanov, R.R. Safin, P.A. Kainov, Int. Multi-Conf. on Ind. Eng. and Mod. Tech. FarEastCon 2018, 8602648 (2018) DOI: 10.5593/sgem2019/4.1/S17.064

20. R.R. Safin, N.R. Galyavetdinov, S.R. Mukhametzyanov, A.R. Shaikhutdinova, R.R. Khasanshin, Int. Multidis. Sci. GeoConf. Surv. Geol. and Min. Ec. Man., SGEM 2019, 19 (4.1), 503-509 (2019) DOI: 10.5593/sgem2019/4.1/S17.064 